\title{
Status and growth trend of draught animals population in Ethiopia
}

\begin{abstract}
The aim of this study was to review the fragmented information on draught animal population dynamics and delivering information for improved production and management plan of a country. A retrospective type of study was used. All research findings, annual report series of agricultural sample survey (1996-2017) and FAOSTAT were reviewed. After checking consistency and large area coverage data from 20052017 were used for final growth trend analysis. Simple descriptive statistics and linear models were employed to show the trends. The current study showed that there was a steady growth in camel, horse, and donkey and mule population. The highest growth rates were observed $61.29 \%$ in camel, $34.62 \%$ in donkey, $24 \%$ in mule and $18.4 \%$ in horse population. Draught animals are essential to the livelihoods of many households in rural and urban areas of Ethiopia. Therefore attention should be given to these animals.
\end{abstract}

Keywords: draught animal, population growth, camel, horse, donkey
Volume 6 Issue I - 2017

\author{
Belay Zeleke \\ Arba Minch University, Ethiopia
}

Correspondence: Belay Zeleke, Arba Minch University, College of Agricultural Sciences, P.O. Box 2I Arba Minch Ethiopia,Tel +2519205I7756, Email belayzeleke63@yahoo.com

Received: August 19,2017| Published: October 03, 2017

\section{Introduction}

Naturally endowed with different agro-ecological zones and suitable environmental conditions, Ethiopia is a home for many livestock species and suitable for livestock production. The livestock sector has been contributing considerable portion to the economy of the country, and still promising to rally round the economic development of the country. It contributes 12 and $33 \%$ of the total and agricultural Gross Domestic Product (GDP), respectively, and provides livelihood for $65 \%$ of the population. The sector also accounts for $12-15 \%$ of the total export earnings.

Ethiopia is believed to have the largest livestock population in Africa. ${ }^{2,3}$ An estimate indicates that the country is a home for 59.5 million cattle, 30.7 million sheep, 30.2 million goats and 56.53 million poultry. ${ }^{3}$ Similarly, the country has the highest draft animal population in the continent. It accounts $4.19 \%$ of global camel population, $34.5 \%$ of total Africa's and $3.45 \%$ of global horse populations, and the largest donkey population in the world ${ }^{4}$ and generally nearly $40 \%$ of Africa's equine population. ${ }^{5}$

Metaferia et al. ${ }^{6}$ reported that cattle, sheep and goats are the three most important livestock species that have a considerable important to the GDP of the country. Though they are very useful in every farming activity the importance of draught animals have been overlooked; even most of the genetic characterization studies focused on cattle, sheep, goat and poultry. Unlike camel which some literatures are available,$^{7-11}$ works on horse and donkey are scarce. Despite they are multipurpose and large in number little attention has been given for draught animal genetic resource.

Draught animal are animals used for work. Horse, Donkey and Mule are among draught animals or working animals. They are found mainly in temperate, semi-arid or highland areas. The Ethiopian domestic donkey is indigenous to Africa. Its ancestors are the Nubian wild ass, Equus asinus africanus and the Somali wild ass, Equus asinus somaliensis. Donkeys are the cheapest option for the Ethiopian family. They are relatively inexpensive to buy in comparison to horses, mules and oxen. As described by Befikadu et al. ${ }^{12}$ on average, a donkey costs 45-50 dollar per head and lives for an average of nine years. The donkey able to survive on poor quality food and many families leave their donkeys to scavenge. Donkeys are hardy and will live longer than other species in the same conditions. Donkeys and horses are herd animals and will happily live in groups with donkeys or animals of a different species such as, sheep and goats. Donkeys and horse are very friendly animals and enjoy the company of humans. They are easily trained and are suitable for handling by children especially donkey.

The camel (Camillus dromedaries) is an important livestock species uniquely adapted to arid and semi-arid environments. It is most numerous in the arid areas of Africa, particularly in the arid lowlands of Eastern Africa namely, Somalia, Sudan, Ethiopia, Kenya and Djibouti. ${ }^{13}$ Camels have played critical roles in a range of human societies. multi-purpose animal and unlike any other domesticated animal, has been utilized by humans for centuries for transport, traction power, milk, meat, wool, skin and even fuel.

Generally, the Draught animals provide power for the cultivation of the smallholdings and for crop threshing virtually all over the country and are also essential modes of transport to take holders and their families long-distances, to convey their agricultural products to the market places and bring back their domestic necessities. ${ }^{3}$ Hence, improving the productivity of draught animals through breeding and improved managements will result in increasing opportunities of profit or income for the households of rural areas of Ethiopia. So, understanding the growth trend and spatial distribution of these livestock species is crucial in order to devise a feasible and geographically targeted livestock development policy. However, well-documented and recent information which can help to devise this kind of development plan in Ethiopia is lacking. Therefore, this study attempts to fill the gaps in this regard. Based on the outlined background, the objective of this paper was to review research findings of population dynamics, synthesize the fragmented information and thereby deliver information for improved management and breeding program of draught animals in Ethiopia. 


\section{Methodology}

\section{Description of the study area}

The study was conducted in Ethiopia. Ethiopia is a landlocked country found in the horn of Africa. It is geographically located between $32^{\circ} 30^{\prime}-48^{\circ} 00^{\prime} \mathrm{E}$ and $3^{\circ} 00^{\prime}-15^{\circ} 00^{\prime} \mathrm{N}$. It covers a land area of 1.04 million $\mathrm{km}^{2} .{ }^{14}$ Ethiopia is suitable for agricultural production and it is also a home for different livestock species. In 1991, when the present federal government of Ethiopia came to power, it launched Agricultural Development Led Industrialization (ADLI) strategy. ${ }^{15}$ The Ethiopian government has also formulated a five year growth and transformation plan (GTP) 2010/11-2014/2015 and 2015/16$2019 / 20$ to carry forward the important strategic direction pursued over last couple of decades. In the GTP, special emphasis was given to agricultural and rural development, industry and infrastructure. The plan takes in to account two alternative economic growth scenarios. The high case scenario assumes that the GDP and the Agricultural Value Added achieved in 2009 will double by the end of the GTP period, 2014/2015. ${ }^{16}$

\section{Study design and source of data}

A retrospective type of study was carried out based upon the secondary data obtained from diverse sources. All information and research findings that have relation with population dynamics were reviewed. District level data pertaining to different aspects of draught animal were collected from the Livestock Census, and FAOSTAT reports. In addition, information on the size of Ethiopian livestock populations were obtained from the CSA (http://www.csa.gov.et/) annual report series, the agricultural sample survey (CSA, 19962017), FAOSTAT (1996-2014) and agricultural census. ${ }^{17}$ The annual Livestock Sample Survey covered the rural agricultural population in all the regions of the country except the non sedentary population of three zones of Afar and six zones of Somali regions. The agricultural census and annual agricultural sample survey cover only three (Jijiga, Liben, and Shinile) of the nine administrative zones of the Somali region, which may not accurately represent Somali region as a whole. In order to cover the rest six zones in Somali region, an aerial survey was conducted in 2003. Livestock Development Master Plan Study (LDMPS) was also made an estimate in 2005/06 to incorporate all pastoral area animals from administrative zones not sampled by CSA. These data sets were used to estimate the livestock population of the Somali region. Therefore, after checking the consistency of the data the growth trend was calculated from 2005-2017 in the final analysis.

\section{Data analysis methods}

The national draught animal population growth trend was calculated using Microsoft Excel. Simple descriptive statistics and linear models were employed to show the trends.

\section{Result and discussion}

\section{Draught animal population growth trend}

Camel population: All camels in Ethiopia are dromedaries (Camelus dromedarius). The study shows that the cattle population in sedentary areas of Ethiopia continues to grow. From 1996 to 2016 the camel population grew from 247 thousand to 1.21 million with an average increment of $10 \%$ of the population. The draught animal population of the sedentary part of the country from 2000 to 2016 is presented in Table 1. The camel population shows an increment from time to time.
But the numbers were declined in 2008 by $-24 \%$ (Table 1 ). These could be attributed the recurrent drought which cause mass death of the animal and migration of sedentary farmers to get better feed and water source and left behind as pastoral. As reported by FAO (2013) East Africa has $44 \%$ of the worlds' camel population. In addition, $66 \%$ of camel milk and $22 \%$ of camel meat produced in this region. Likewise form the Camels Aged 4Years and Older 2.61\% used for meat production, $31.67 \%$ for milk, $28.47 \%$ for transportation, 2.33 for farming activity and 34.9 used for other purposes (viz: entertainment, social value, prestige, wealth and saving etc) (Figure 1). ${ }^{3}$ It is believed that the camel populations in developing country are underestimated due to the fact that camels are found on the marginal area of the countries. Similarly, livestock population estimates in Ethiopia are based on data collected from sedentary areas, which excludes large pastoral areas of Afar and Somali regions that have huge camel population. Nevertheless the country owns $4.19 \%$ the worlds' camel population.

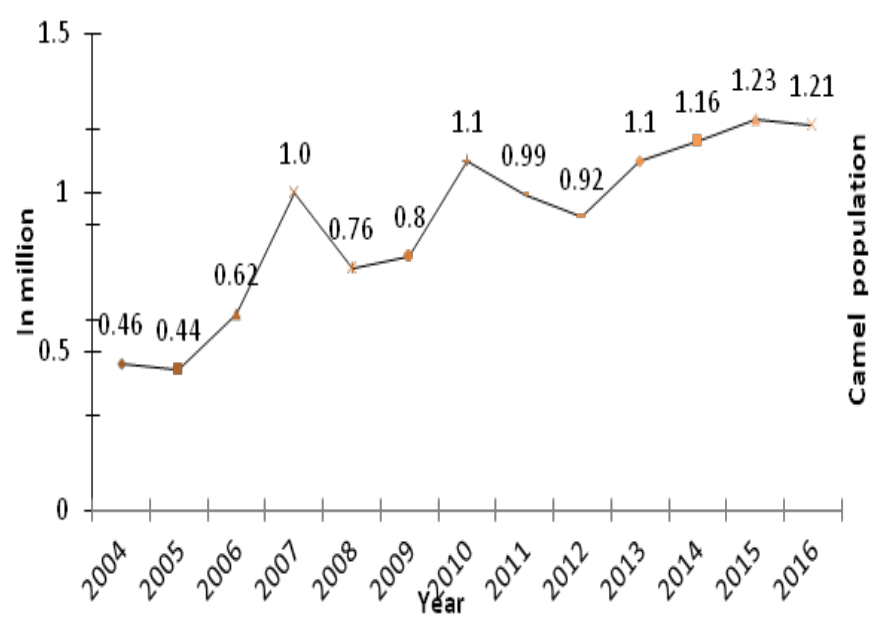

Figure I Trends of camel population in years.

Horse population: The change of horse population in Ethiopia is presented in Figure 2. The highest population change (7.23\%) was observed in 2007 where as the lowest was observed in 2012. As indicated in Table 1 there was a continual growth until 2011 then it showed slight decrement. However, due to the efforts of the government and agricultural offices the population started to increase in 2013. Horses are present throughout the world. Horses have been with humans throughout history and have served a variety of practical purposes. Likewise in Ethiopia horses serve as a means of transport (64.72\%), a work animal in agriculture (18.62), entertainment and others (16.65\%). The world's horse population was estimated to be 58.9 million. ${ }^{4}$ With the 2.03 million head of horses reported in CSA, ${ }^{18}$ Ethiopia accounts for about $34.5 \%$ of total Africa's and $3.45 \%$ of global horse populations, respectively.

Mule population: Unlike horse and donkey which belong to equine group mule are sterile in nature. They are a hybrid cross between Donkey and horse. A horse has 64 chromosomes and a donkey has 62. The mule has 63 chromosomes. But because of the odd chromosome they can't reproduce. However mule inherits the best traits from its parent. They inherit high strength endurance and patience from donkey and athletic ability, speed and equine beauty from horse. The populations of mule in Ethiopia have been increased from time to time. Similarly their contributions have increased from time in the life of the farming activity (Figure 3). Due to their strength $88.98 \%$ of Mules Aged 3 Years and Older used for transportation. In addition, 
9.5\% used for draught and $1.46 \%$ of them used for entertainment and other immediate purpose.

Donkey population: Domestic donkeys are the least studied and neglected mammals of the world. ${ }^{19}$ Despite the fact that donkeys are important in the development of rural economy, however, it generally received very little scientific attention. The trend and change of population in Ethiopia is presented in Figure $4 \&$ Table 1. As indicated in Table 1 the highest change (24\%) observed in 2010. Whereas, the lowest change $(-7.75 \%)$ was observed in 2009 . Donkeys are essential to the livelihoods of many households in rural and urban areas of Ethiopia, relieving families from repetitive and energy-consuming tasks. ${ }^{12}$ Similarly, as reported by CSA (2017), of the donkey population above three years; 82.76 of the donkey used for transportation, 14.55 for draught 2.67 used for entertainment and other purposes.

Table I Draught animal population (in Millions) and their rate of changes throughout years

\begin{tabular}{|c|c|c|c|c|c|c|c|c|}
\hline & \multicolumn{2}{|c|}{ Horse } & \multicolumn{2}{|c|}{ Donkey } & \multicolumn{2}{|c|}{ Camel } & \multicolumn{2}{|l|}{ Mule } \\
\hline & No & Rate of change & No & Rate of change & No & Rate of change & No & Rate of change \\
\hline 2000 & 1.15 & & 3.06 & & 0.4 & & 0.22 & \\
\hline 2001 & 1.25 & $8.70 \%$ & $3.4 I$ & $11.44 \%$ & 0.41 & $2.50 \%$ & 0.26 & $18.18 \%$ \\
\hline 2002 & 1.48 & $18.40 \%$ & 3.9 & $14.37 \%$ & 0.42 & $2.44 \%$ & 0.34 & $34.62 \%$ \\
\hline 2003 & 1.5 & $1.35 \%$ & 3.8 & $-2.56 \%$ & 0.435 & $3.57 \%$ & 0.25 & $-28.64 \%$ \\
\hline 2004 & 1.52 & $1.33 \%$ & 3.93 & $3.42 \%$ & 0.46 & $5.75 \%$ & 0.31 & 0.24 \\
\hline 2005 & 1.57 & $3.29 \%$ & 4.29 & $9.16 \%$ & 0.44 & $-4.35 \%$ & 0.34 & $9.68 \%$ \\
\hline 2006 & 1.66 & $5.73 \%$ & 4.5 & $4.90 \%$ & 0.62 & $40.91 \%$ & 0.33 & $-2.94 \%$ \\
\hline 2007 & 1.78 & $7.23 \%$ & 5.57 & $23.78 \%$ & I & $61.29 \%$ & 0.38 & $15.15 \%$ \\
\hline 2008 & 1.79 & $0.56 \%$ & 5.42 & $-2.69 \%$ & 0.76 & $-24.00 \%$ & 0.335 & $-11.84 \%$ \\
\hline 2009 & 1.9 & $6.15 \%$ & 5 & $-7.75 \%$ & 0.8 & $5.26 \%$ & 0.3 & $-10.45 \%$ \\
\hline 2010 & 2 & $5.26 \%$ & 6.2 & $24.00 \%$ & I.I & $37.50 \%$ & 0.38 & $26.67 \%$ \\
\hline 2011 & 1.96 & $-2.00 \%$ & 6.4 & $3.23 \%$ & 0.99 & $-10.00 \%$ & 0.37 & $-2.63 \%$ \\
\hline 2012 & 1.91 & $-2.55 \%$ & 6.75 & $5.47 \%$ & 0.92 & $-7.07 \%$ & 0.35 & $-5.41 \%$ \\
\hline 2013 & 1.96 & $2.62 \%$ & 6.95 & $2.96 \%$ & I.I & $19.57 \%$ & 0.36 & $2.86 \%$ \\
\hline 2014 & 2.03 & $3.57 \%$ & 7.43 & $6.91 \%$ & 1.16 & $5.45 \%$ & 0.4 & $11.11 \%$ \\
\hline 2015 & 2.08 & $2.46 \%$ & 7.88 & $6.06 \%$ & 1.23 & $6.03 \%$ & $0.4 I$ & $2.50 \%$ \\
\hline 2016 & 2.16 & $3.85 \%$ & 8.44 & $7.11 \%$ & 1.21 & $-1.63 \%$ & 0.41 & $0.00 \%$ \\
\hline
\end{tabular}

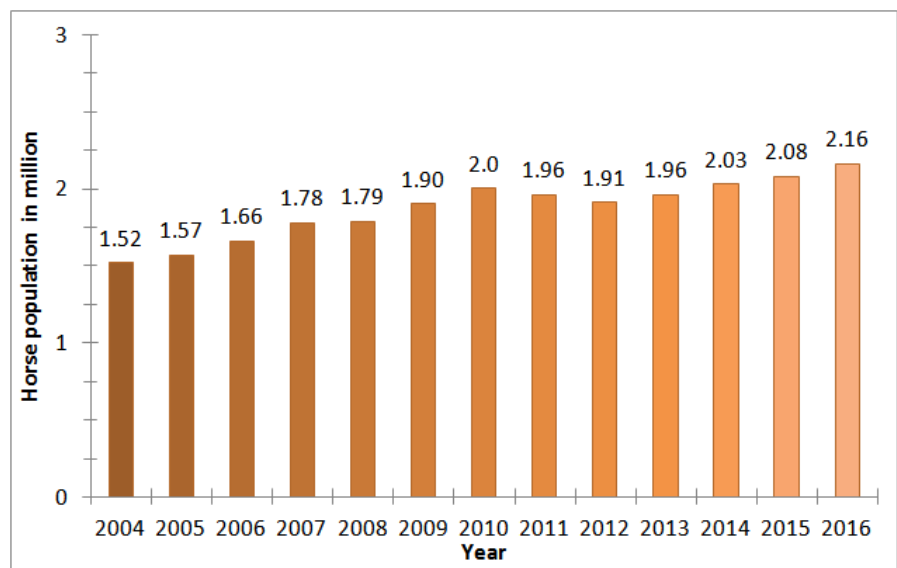

Figure 2: Tends of horse population.

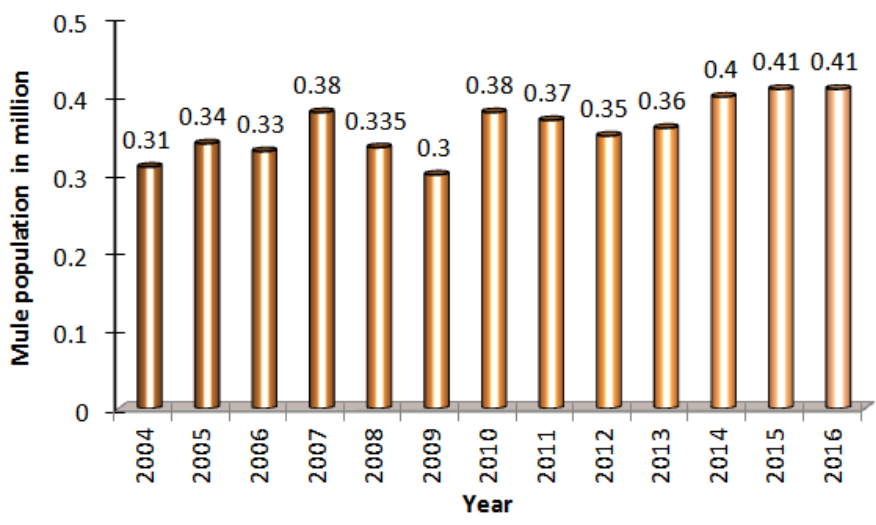

Figure 3: Trends of mule population. 


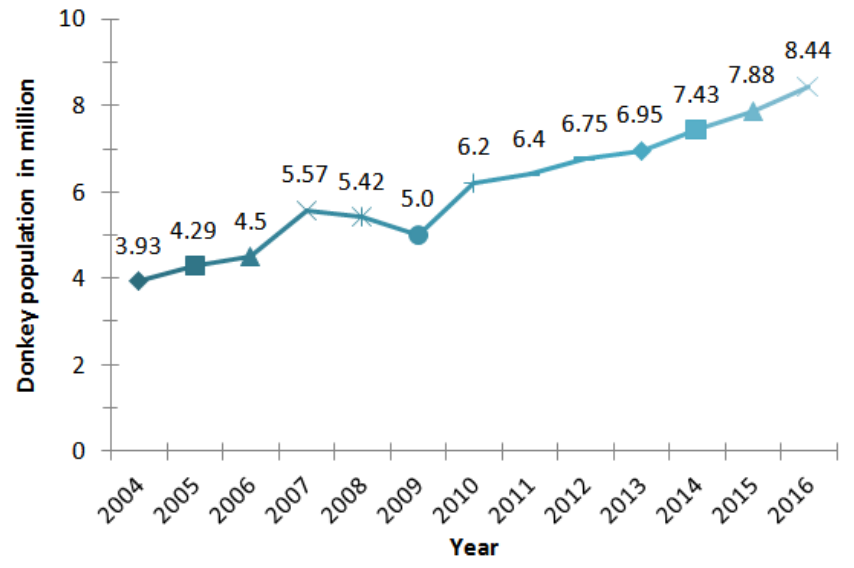

Figure 4: Trend of Donkey populations in Ethiopia.

\section{Conclusion and recommendation}

The population trend showed that there is a steady growth in the population. The camel population changed from 247 thousand to over 1.2 million, the horse population increased more than 2 million where as the donkey population is the largest in the world. Draught animals are essential to the livelihoods of many households in rural and urban areas of Ethiopia, relieving families from repetitive and energyconsuming tasks, serving as transportation, and support in farming activity and even used for entertainment. However, little attention has been given to these animals therefore due attention is required to characterize and identify the status each breeds. Hence, further work should be done on camel characterization at molecular level, equine identification and conservation.

\section{Acknowledgments}

I would like to acknowledge Arba Minch University for supporting this work.

\section{Conflict of interest}

The author declares that there is no conflict of interest.

\section{References}

1. FAO. Statistical year book. Food and Agriculture Organization of the United Nations, Rome, Italy, 2013. p. 1-307.

2. Tilahun H, Schmidt E. Spatial Analysis of Livestock Production Patterns in Ethiopia. ESSP II Working Paper 44. International Food Policy Research Institute/Ethiopia Strategy Support Program II. Addis Ababa, Ethiopia; 2012.

3. CSA. Agricultural Sample Survey, 2016/17 (2009E.C.), Volume II: Report on Livestock and livestock characteristics (Private peasant holdings). Statistical Bulletin 585. Central Statistical Agency (CSA). Addis Ababa, Ethopia: Federal Democratic Republic of Ethiopia; 2017.

4. FAO. Statistical year book. Food and Agriculture Organization of the United Nations. Rome, Italy; 2014.
5. Alemu G, Azage T, Alemu Y. Research need of donkey utilization in Africa. In: Fielding D, Starkey P, editors. Donkeys, people and development. A resource book of the Animal Traction Network for Eastern and Southern Africa (ATNESA). Technical Center for Agricultural and Rural Cooperation (CTA), Wageningen, The Netherlands; 2004:77-79.

6. Metaferia F, Cherenet T, Gelan A, et al. A Review to Improve Estimation of Livestock Contribution to the National GDP. Ministry of Finance and Economic Development and Ministry of Agriculture. Addia Ababa, Ethiopia; 2011.

7. Simenew Keskes Melaku. Characterization of camelus dromedarius in ethiopia: production systems, reproductive performances and infertility problems. Ethiopia: $\mathrm{PhD}$ thesis Addis Ababa University; 2014.

8. Tadesse Yosef, Mengistu Urge, Solomon Abegaz, et al. Husbandry and breeding practices of dromedary camels among pastoral communities of Afar and Somali regional states, Ethiopia. JAEID. 2014;108(2):167-189.

9. Berhanu Bekele. Phenotypic Characterization of Camels and their Production System in Yabello and Melka Soda Districts, Oromia Regional State, Ethiopia. Haramaya Ethiopia: MSc Thesis Haramaya University. 2015.

10. Sisay F, Awoke K. Review on Production, Quality and Use of Camel Milk in Ethiopia. J Fisheries Livest Prod. 2015;3:3.

11. Galma Wako, Menfese Tadesse, Ayana Angassa. Camel management as an adaptive strategy to climate change by pastoralists in southern Ethiopia. Ecological Processes. 2017;6:26.

12. Befikadu Zewdie, Kiflay Welday, Sanjoy Kumar Pal. Conservation of Indigenous Donkey Breeds of Ethiopia: A Review. International Journal of Interdisciplinary and Multidisciplinary Studies (IJIMS). 2015;2(6):13-22.

13. Dejene Takele Gebissa. Husbandry Practices and Utilization of Camel Products in Borana Zone of Southern Oromia, Ethiopia. Science Research. 2015;3(4):191-197.

14. CIA. The World Factbook. Ethiopia. 2014.

15. Benin S, Ehui S, Pender J. Policies for livestock development in the Ethiopian highlands. Environ Dev Sustain. 2003;5(3-4):491-510.

16. MOFED. Federal Democratic Republic of Ethiopia, Growth and Transformation Plan 2010/11 - 2014/15. Volume I: Main Text. Ministry of Finance and Economic Development, Addis Ababa, Ethiopia; 2010. p. 1-135.

17. CSA. Ethiopian Agricultural Sample Enumeration, 2001/02 (1994 E.C). Central Agricultural Census Commission, Central Statistical Agency (CSA). Federal Democratic Republic of Ethiopia, Addis Ababa, Ethiopia; 2002.

18. CSA. Agricultural Sample Survey, 2013/14 (2006 E.C.). Volume II: Report on Livestock and livestock characteristics (Private peasant holdings). Statistical Bulletin 573. Central Statistical Agency (CSA), Federal Democratic Republic of Ethiopia, Addis Ababa, Ethiopia; 2014.

19. Blench RM. A history of donkeys, wild asses and mules in Africa. In: Blench RM, MacDonald KC, editors. The origin and development of African livestock: archaeology, genetics, linguistics and ethnography. UCL Press; 2000. p. 339-354. 